Article

\title{
Atmospheric Effect Analysis and Correction of the Microwave Vegetation Index
}

\author{
Da-Bin Ji, Jian-Cheng Shi *, Husi Letu, Tian-Xing Wang and Tian-Jie Zhao \\ State Key Laboratory of Remote Sensing Science, Institute of Remote Sensing and Digital Earth, \\ Chinese Academy of Sciences, No. 20 Datun Road, Chaoyang District, Beijing 100101, China; \\ jidb@radi.ac.cn (D.-B.J.); husiletu@radi.ac.cn (H.L.); wangtx@radi.ac.cn (T.-X.W.); zhaotj@radi.ac.cn (T.-J.Z.) \\ * Correspondence: shijc@radi.ac.cn; Tel.: +86-010-6483-8048
}

Academic Editors: Alexander Kokhanovsky and Richard Müller

Received: 19 December 2016; Accepted: 9 June 2017; Published: 14 June 2017

\begin{abstract}
Microwave vegetation index (MVI) is a vegetation index defined in microwave bands. It has been developed based on observations from AMSR-E and widely used to monitor global vegetation. Recently, our study found that MVI was influenced by the atmosphere, although it was calculated from microwave bands. Ignoring the atmospheric influence might bring obvious uncertainty to the study of global vegetation. In this study, an atmospheric effect sensitivity analysis for MVI was carried out, and an atmospheric correction algorithm was developed to reduce the influence of the atmosphere. The sensitivity analysis showed that water vapor, clouds and precipitation were main parameters that had an influence on MVI. The result of the atmospheric correction on MVI was validated at both temporal and spatial scales. The validation showed that the atmospheric correction algorithm developed in this study could obviously improve the underestimation of MVI on most land surfaces. Seasonal patterns in the uncorrected MVI were obviously related to atmospheric water content besides vegetation changes. In addition, global maps of MVI showed significant differences before and after atmospheric correction in the northern hemisphere in the northern summer. The atmospheric correction will make the MVI more reliable and improve its performance in calculating vegetation biomass.
\end{abstract}

Keywords: microwave vegetation index; atmospheric correction; water vapor; cloud liquid water

\section{Introduction}

Vegetation is an important land surface cover in the Earth's ecosystems. Improving the ability to monitor global vegetation and obtaining accurate measurements of vegetation parameters are of great importance to the study of the global carbon cycle, net primary productivity, and security of grain production in agriculture. In optical remote sensing, leaf area index (LAI) [1-3], normalized difference vegetation index (NDVI) and other improved vegetation indices [4,5] are widely used to monitor vegetation. These vegetation indices acquired from optical remote sensing have greatly helped us to understand the characteristics of vegetation at a regional and global scale. However, a major limitation of the NDVI and similar indices is that the optical sensors can only monitor a very thin layer of canopy [6]. The lack of information on the woody part of these optical vegetation indices will significantly influence their application in the study of the global carbon cycle.

Microwaves are also sensitive to variations of vegetation at some particular bands. Compared to optical remote sensing sensors, passive microwave sensors are able to provide land surface observations in all weather conditions. The ability for vegetation to be detected from passive microwave sensors has been confirmed in a number of previous studies. Like optical remote sensing, vegetation indices built from band combinations of passive microwave observations were also used in these studies. These vegetation indices include microwave polarization difference temperatures (MPDT) at $37 \mathrm{GHz}[7,8]$, the normalized 
microwave polarization difference index (MPDI) at frequencies $10 \mathrm{GHz}$ and $36 \mathrm{GHz}$ [9], the microwave emissivity difference vegetation index (EDVI) at $19 \mathrm{GHz}$ and $37 \mathrm{GHz}$ [10], the microwave vegetation indices (MVIs) at frequencies $6 \mathrm{GHz}, 10 \mathrm{GHz}$ and $19 \mathrm{GHz}$ [6], and improved MVIs by considering measurements at different observation angles of WindSat [11,12]. The information of both leafy and woody parts of vegetation could be obtained from these microwave vegetation indices due to long wavelengths and the sensitivity of microwaves [6]. The long wavelength of microwaves is much larger than the diameter of cloud particles and makes it possible to acquire vegetation information in all weather conditions. This is why few of these vegetation indices from passive microwave sensors consider the influence of the atmosphere when acquiring vegetation information. However, the atmosphere has an obvious influence on microwave vegetation indices, especially when observations are made at frequencies such as $19 \mathrm{GHz}$ and $37 \mathrm{GHz}$, according to our analysis.

Water vapor, clouds, precipitation, and oxygen are main constituents in the atmosphere that contaminate microwave signals emitted from the land surface, and are received by passive microwave sensors. Water vapor and oxygen influence the microwave signal by means of absorption. During cloudy and rainy days, absorption and scattering effects of water droplets are two main methods attenuating microwave radiation signals emitted from the Earth's surface. Although the influence of these constituents in atmosphere is not too significant on a single polarized microwave band at low frequency, it can be enlarged by means of polarization difference or ratio when calculating microwave vegetation indices. Therefore, the consideration of atmospheric influence will have great potential to improve the accuracy of microwave vegetation indices.

In this study, the recently developed MVI in [6] will be taken as an example. The MVI is calculated from dual-frequency and dual-polarization of AMSR-E measurements. We will first analyze the influence of atmosphere on MVI using a one-dimensional microwave radiative transfer model (1DMWRTM) [13,14], and atmosphere profiles from radiosonde observations. At the same time, an atmospheric correction method will also be developed to eliminate the influence of water vapor and clouds on MVI. The atmospheric correction will obviously improve the ability of MVI to monitor vegetation information at regional or global scales, and further extend the application of microwaves in the study of global carbon cycles and the Earth's ecosystem. In the next section, the effect of atmosphere on MVI will first be analyzed, and then an atmospheric correction method will be developed based on the analysis. The results of atmospheric correction are mainly discussed in Section 3. Section 4 concludes this study.

\section{Atmospheric Effect Analysis and Correction}

\subsection{Basic Theory}

MVI is calculated from dual-frequency and dual-polarization of AMSR-E measurements. There are two parameters in MVI. One is $A$ parameter, and the other is $B$ parameter. The two parameters are expressed in Equations (1) and (2) respectively [6].

$$
\begin{gathered}
A\left(f_{1}, f_{2}\right)=\frac{1}{2}\left[T b_{f_{2}}^{v}+T b_{f_{2}}^{h}-B\left(f_{1}, f_{2}\right) \cdot\left(T b_{f_{1}}^{v}+T b_{f_{1}}^{h}\right)\right] \\
B\left(f_{1}, f_{2}\right)=\frac{T b_{f_{2}}^{v}-T b_{f_{2}}^{h}}{T b_{f_{1}}^{v}-T b_{f_{1}}^{h}}
\end{gathered}
$$

where $f_{1}$ and $f_{2}$ represent two frequencies of AMSR-E. Tb is the brightness temperature of a frequency derived from AMSR-E. $v$ and $h$ represent vertical and horizontal polarizations, respectively. Both parameters $A$ and $B$ are sensitive to vegetation. The $A$ parameter will increase and $B$ parameter will decrease, as the vegetation canopy becomes thicker [6]. As the $A$ parameter is calculated based on the $B$ parameter, we will mainly discuss the atmosphere effect on the $B$ parameter in this study. For clarity, $M V I \_B$ will be used to represent the $B$ parameter throughout this paper. According to 
Shi et al. [6], the valid range of $M V I \_B$ is between 0 and 1 . The higher the vegetation cover becomes, the lower the value of $M V I \_B$ will be. For bare surfaces, the estimated $M V I \_B$ will be very close to 1 .

When there is no atmosphere, brightness temperatures received by microwave sensors onboard satellites can be expressed as a multiplication of land surface emissivity $(\varepsilon)$ and land surface temperature $\left(T_{S}\right)$. So, Equation (2) can be expressed as Equation (3):

$$
M V I \_B\left(f_{1}, f_{2}\right)=\frac{T b_{f_{2}}^{v}-T b_{f_{2}}^{h}}{T b_{f_{1}}^{v}-T b_{f_{1}}^{h}}=\frac{\Delta T b_{f_{2}}}{\Delta T b_{f_{1}}}=\frac{T_{s} \cdot \varepsilon_{f_{2}}^{v}-T_{s} \cdot \varepsilon_{f_{2}}^{h}}{T_{s} \cdot \varepsilon_{f_{1}}^{v}-T_{s} \cdot \varepsilon_{f_{1}}^{h}}=\frac{\varepsilon_{f_{2}}^{v}-\varepsilon_{f_{2}}^{h}}{\varepsilon_{f_{1}}^{v}-\varepsilon_{f_{1}}^{h}}=\frac{\Delta \varepsilon_{f_{2}}}{\Delta \varepsilon_{f_{1}}}
$$

where $\Delta T b$ is the polarization difference of brightness temperature at a particular frequency, and $\Delta \varepsilon$ is the polarization difference of surface emissivity at a particular frequency. According to Equation (3), the $M V I \_B$ parameter can be expressed as a ratio of the polarization difference of surface emissivity at two frequencies when the atmosphere effect is not considered.

When considering the effect of the atmosphere, and assuming that the atmosphere is a non-scattering, plane-parallel atmosphere with a non-blackbody surface boundary condition, the brightness temperature received by the microwave sensor onboard a satellite can be expressed as follows [15-17]:

$$
\begin{aligned}
T b_{f} & =\varepsilon_{f} T_{s} t_{f}+\int_{p_{s}}^{0} T(p) \frac{\partial t_{f}(p, 0)}{\partial p} d p+\left(1-\varepsilon_{f}\right) t_{f}^{2} \int_{p_{s}}^{0} \frac{T(p)}{\left[t_{f}(p, 0)\right]^{2}} \frac{\partial t_{f}(p, 0)}{\partial p} d p \\
& +\left(1-\varepsilon_{f}\right) t^{2} T_{s p a c e}
\end{aligned}
$$

where $T b_{f}$ is the upward brightness temperature observed by the satellite at the top of the atmosphere and frequency $f ; \varepsilon_{f}$ is the surface emissivity at frequency $f ; p_{s}$ is the surface pressure, where the subscript s denotes surface value; $t_{f}(p, 0)$ is the atmospheric transmittance for a layer between pressure level $p$ and $p=0$ at frequency $f ; T_{\text {space }}$ is the cosmic background temperature, and its value is $2.7 \mathrm{~K}$.

When calculating the brightness temperature difference between vertical and horizontal polarization, although a few parts of the atmospheric contribution which includes the upward radiation of the atmosphere and part of the downward radiation of the atmosphere is cancelled out, the atmosphere still influences radiation from the Earth's surface by transmittance of the atmosphere $\left(t_{f}\right)$ and the downward radiation of atmosphere. Besides, the polarization difference of a frequency will also cancel out a large part of the ground surface contribution. The decrease of surface contribution will enlarge the proportion of the contribution of atmosphere in polarization difference of brightness temperature $\left(\Delta T b_{f}\right)$. In addition, as the ability of the atmospheric attenuation to the radiation at various frequencies is different, the ratio of $\Delta T b_{f}$ at two frequencies will further enhance the proportion of the atmosphere contribution. Thus, when calculating the ratio of the brightness temperature polarization difference of two frequencies, the atmosphere will have a significant contribution to the ratio, and the formula for calculating the ratio can be written in the form of Equation (5):

$$
\begin{aligned}
\operatorname{MVI\_ B}\left(f_{1}, f_{2}\right)^{*} & =\frac{\Delta T b_{f_{2}}}{\Delta T b_{f_{1}}}=\frac{\Delta \varepsilon_{f_{2}}}{\Delta \varepsilon_{f_{1}}} \cdot \frac{T_{s} t_{f_{2}}-t_{f_{2}}^{2} \int_{p_{s}}^{0} \frac{T(p)}{t_{f_{2}}^{2}(p, 0)} \cdot \frac{\partial t_{f_{2}}(p, 0)}{\partial p} d p-t_{f_{2}}^{2} T_{\text {space }}}{T_{s} t_{f_{1}}-t_{f_{1}}^{2} \int_{p_{s}}^{0} \frac{T(p)}{t_{f_{1}}^{2}(p, 0)} \cdot \frac{\partial f_{f_{1}}(p, 0)}{\partial p} d p-t_{f_{1}}^{2} T_{\text {space }}} \\
& =\frac{\Delta \varepsilon_{f_{2}}}{\Delta \varepsilon_{f_{1}}} \cdot f\left(T_{s}, \text { atmos }\right)
\end{aligned}
$$

where $M V I_{-} B\left(f_{1}, f_{2}\right)^{*}$ is the $B$ parameter of MVI without removing the effect of the atmosphere. $f\left(T_{s}\right.$, atmos $)$ is a function of land surface temperature $T_{s}$, and atmosphere parameters. By combining Equations (3) and (5), the atmosphere-corrected $M V I \_B$ parameter can be expressed in the form of Equation (6)

$$
M V I \_B\left(f_{1}, f_{2}\right)=M V I \_B\left(f_{1}, f_{2}\right)^{*} / f\left(T_{s}, \text { atmos }\right)
$$


If $M V I_{-} B\left(f_{1}, f_{2}\right)^{*}, T_{S}$ and parameters of the atmosphere are given, the atmosphere-corrected $M V I \_B\left(f_{1}, f_{2}\right)$ can be directly calculated according to Equation (6).

\subsection{Atmospheric Effect Analysis}

As mentioned above, water vapor, oxygen, clouds, and precipitation are primary constituents in the atmosphere that have an influence on the microwave signal. Water vapor has a weak absorption zone at $22.235 \mathrm{GHz}$, and a strong absorption zone at $183 \mathrm{GHz}$. For oxygen molecules, there are two absorption zones, at $60 \mathrm{GHz}$ and at $118.75 \mathrm{GHz}$ [16]. The influence of cloud and rain on microwaves can be attributed to scattering and the absorption effect of water droplets. When the frequency is below $22 \mathrm{GHz}$, absorption of water droplets plays an important role in the process of microwave radiative transfer. According to Shi et al. [6], the MVI_B parameter is calculated based on three frequencies, $6.925 \mathrm{GHz}, 10.65 \mathrm{GHz}$, and $18.7 \mathrm{GHz}$. When $f_{1}=6.925 \mathrm{GHz}$ and $f_{2}=10.65 \mathrm{GHz}, M V I \_B$ is called the low frequency microwave vegetation index. When $f_{1}=10.65 \mathrm{GHz}$ and $f_{2}=18.7 \mathrm{GHz}$, $M V I \_B$ is called the high frequency microwave vegetation index. For the convenience of description, $M V I \_B(C, X)$ and $M V I \_B(X, K u)$ are used to represent the two $M V I \_B$ parameters, respectively. As the three frequencies used to calculate $M V I \_B$ parameter are far from the oxygen absorption frequencies, and also because the content of oxygen in the atmosphere is stable, the influence of oxygen on the $M V I \_B$ parameter is very small, and can be ignored. Precipitation indeed has an influence on the $M V I \_B$ parameter. However, it is currently difficult to fully simulate the radiative transfer process of microwaves in precipitation conditions, and it is also hard to acquire highly accurate precipitation data from satellites. So, the effect of precipitation on the $M V I \_B$ parameter will not be discussed in this paper, and will be studied in the future.

Except for oxygen and precipitation, water vapor and clouds are the main constituents that have an influence on $M V I \_B$. In order to analyze the effect of water vapor and clouds on $M V I \_B$, a simulation was carried out under different conditions of water vapor and clouds. Figure 1 shows the simulation of the water vapor effect on $M V I_{-} B(C, X)$ and $M V I_{-} B(X, K u)$. In the simulation, the real values of $M V I \_B(C, X)$ and $M V I \_B(X, K u)$ that were not influenced by atmosphere were both set to 0.404 ; the land surface temperature (LST) was set to $300 \mathrm{~K}$; and the valid range of total precipitable water (TPW) was set from $5.13 \mathrm{~mm}$ to $73.95 \mathrm{~mm}$. According to the simulation in Figure 1, water vapor had a very small influence on $M V I \_B(C, X)$; while, the effect of water vapor on $M V I \_B(X, K u)$ was significant, with the value of $M V I \_B(X, K u)$ decreasing from 0.39 to 0.27 when TPW increased from $5.13 \mathrm{~mm}$ to $73.95 \mathrm{~mm}$. From the point of quantitative analysis, $1 \mathrm{~mm}$ of TPW caused an underestimation of about 0.0002 and 0.0017 in the calculation of $M V I \_B(C, X)$ and $M V I \_B(X, K u)$, respectively. In humid tropical areas, such as the Amazon basin, the existence of water vapor would decrease the value of $M V I \_B(X, K u)$ as observed by satellites.

The simulation of cloud effects on $M V I \_B(C, X)$ and $M V I \_B(X, K u)$ is shown in Figure 2. In the simulation, both $M V I \_B(C, X)$ and $M V I \_B(X, K u)$ that were not influenced by clouds were also set to 0.404; LST and TPW were set to $300 \mathrm{~K}$ and $5.12 \mathrm{~mm}$, respectively. Cloud top and cloud thickness were set to $2.5 \mathrm{~km}$ and $1 \mathrm{~km}$, respectively. The valid range of cloud liquid water ranged from $0.01 \mathrm{~mm}$ to $1.0 \mathrm{~mm}$. As is shown in Figure 2, the value of $M V I_{-} B(C, X)$ decreased from 0.40 to 0.32 , and $M V I \_B(X, K u)$ decreased from 0.40 to 0.19 , when cloud liquid water increased from $0.01 \mathrm{~mm}$ to $1.0 \mathrm{~mm}$. In other words, an increment of $0.1 \mathrm{~mm}$ in cloud liquid water caused a decrease of 0.008 and 0.02 in the retrieval of $M V I \_B(C, X)$ and $M V I \_B(X, K u)$, respectively. The maximum amount of variation of MVI_B parameters caused by cloud liquid water reached up to $0.1 \sim 0.2$. As the valid range of $M V I \_B(C, X)$ and $M V I \_B(X, K u)$ was from 0 to 1 , this amount of variation was significant and should be considered in the calculating of $M V I \_B$ parameters. In general, the low frequency microwave vegetation index $M V I_{-} B(C, X)$ was mainly affected by cloud liquid water; and the high frequency microwave vegetation index $M V I \_B(X, K u)$ was influenced by both water vapor and cloud liquid water. 
According to the simulation mentioned above, the existence of water vapor and clouds in the atmosphere lowered the value of $M V I \_B$ parameters. The higher the increase in the frequencies used to calculate $M V I \_B$ parameters, the greater influence of atmosphere on the $M V I \_B$ parameters. So, consideration and correction of the atmospheric influence would result in more reliable and stable $M V I \_B$ parameters when monitoring global vegetation. As the basic theory for atmospheric correction of $M V I \_B(C, X)$ was the same as that for $M V I \_B(X, K u)$, and also because $M V I \_B(C, X)$ is less influenced by atmosphere, for convenience, only the atmospheric correction of $M V I \_B(X, K u)$ and the results of the analysis on this parameter are discussed in the following sections.

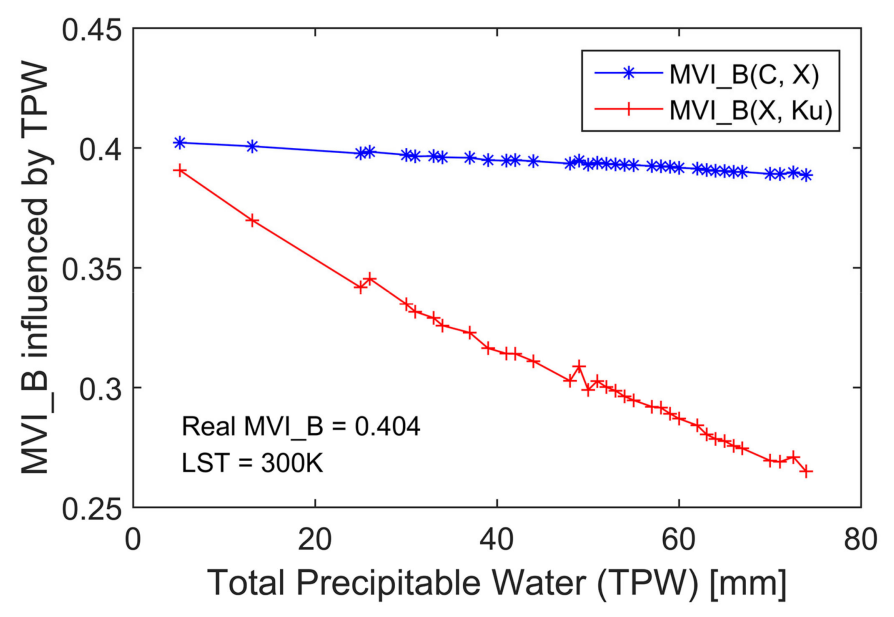

Figure 1. The effect of water vapor on $M V I \_B$ parameters.

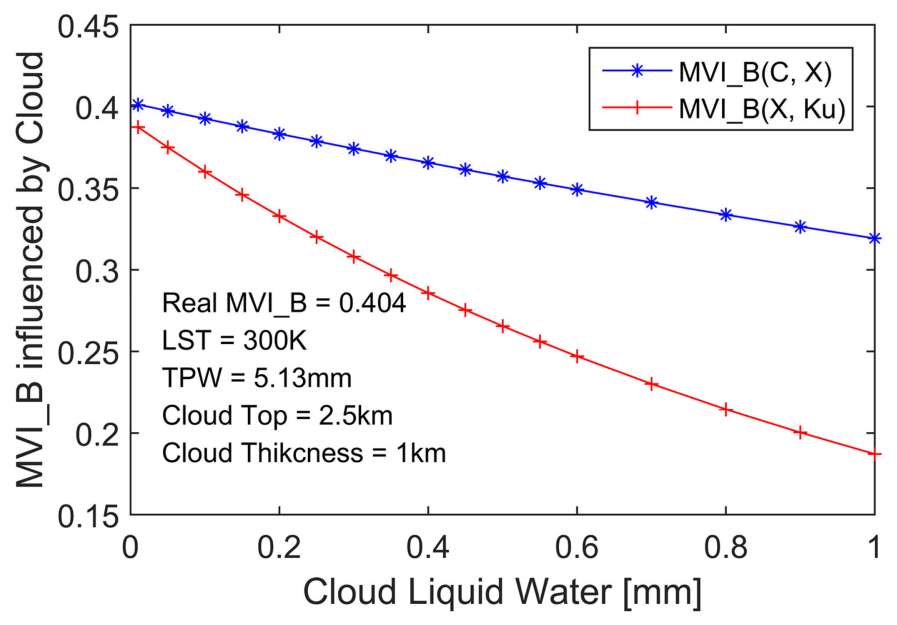

Figure 2. The effect of cloud liquid water on $M V I \_B$ parameters.

\subsection{Atmospheric Effect Correction}

As is discussed above, water vapor and cloud liquid water are main constituents in the atmosphere that affect the atmospheric correction of $M V I \_B(X, K u)$ when there is no precipitation. For water vapor, it has different sensitivities to microwave signals at different atmospheric layers. So, the introduction of a water vapor profile is needed in the atmospheric correction of $M V I \_B(X, K u)$. It is easy to obtain the total column profile of the water vapor. However, it is very difficult to provide an accurate water vapor profile for every pixel of the image in the atmospheric correction of $M V I \_B(X, K u)$. As most of the water vapor is distributed near the surface atmosphere layer, the surface elevation will influence the vertical distribution of water vapor in the atmosphere to some extent. So, the total precipitable water (or total column of water vapor) and surface elevation data are used to approximately substitute the water 
vapor profile in the atmospheric correction. A simulation was carried out to analyze how $M V I \_B(X, K u)$ was influenced in the atmospheric correction, by adding surface elevation data. The outcome of the simulation is shown in Figure 3. In the simulation, $T_{S}$ was set to $266 \mathrm{~K}$, TPW was set to $5 \mathrm{~mm}$, the atmosphere-influenced $M V I \_B(X, K u)^{*}$ was set to 0.7 , and as surface elevation increased from $50 \mathrm{~m}$ to $6500 \mathrm{~m}$, the atmosphere-corrected $M V I_{-} B(X, K u)$ changed from approximately 0.73 to 0.77 . Although the change of $M V I_{-} B(X, K u)$ was small, the simulation showed that the introduction of surface elevation did improve the atmospheric correction of $M V I \_B(X, K u)$. For clouds, besides cloud liquid water (CLW), cloud top height (CTH) was also an important factor that influenced the atmospheric correction of $M V I_{-} B(X, K u)$ according to our simulation. Figure 4 shows a sensitivity simulation of atmosphere-corrected $M V I \_B(X, K u)$ to the change of $C T H$, when surface elevation $=17 \mathrm{~m}$, $T_{s}=300 \mathrm{~K}, \mathrm{TPW}=25 \mathrm{~mm}, \mathrm{CLW}=0.1 \mathrm{~mm}$, and $M V I_{-} B\left(f_{1}, f_{2}\right)^{*}=0.404$. As is shown in the figure, the atmosphere-corrected $M V I \_B(X, K u)$ increased from approximately 0.48 to 0.53 when $\mathrm{CTH}$ changed from $1000 \mathrm{~m}$ to $10,500 \mathrm{~m}$. The increment of $M V I \_B(X, K u)$ means that the introduction of CTH will improve its accuracy in the process of atmospheric correction. To summarize, besides TPW and CLW, the consideration of surface elevation and CTH in atmospheric correction will improve the accuracy of the atmospheric-corrected $M V I \_B(X, K u)$.

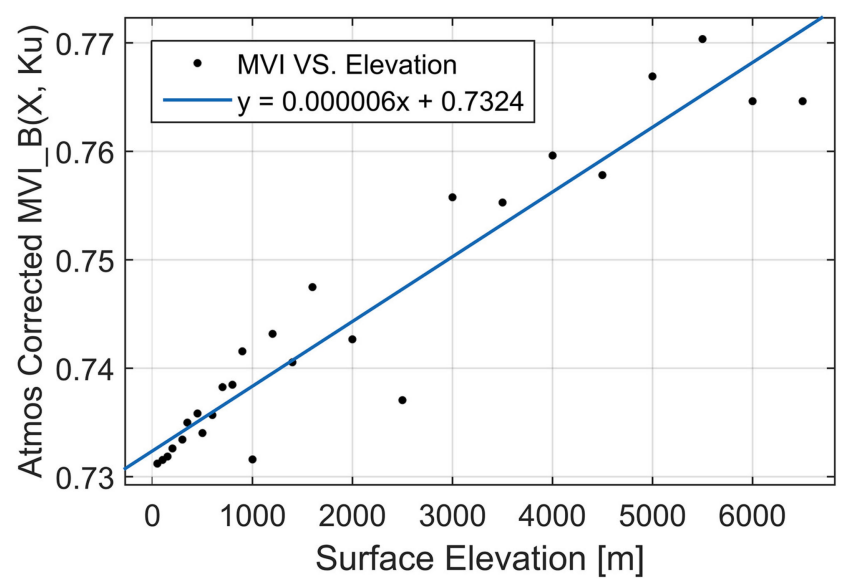

Figure 3. Influence of surface elevation on the atmospheric correction of $M V I \_B(X, K u)$, when land surface temperature $\left(T_{S}\right)=266 \mathrm{~K}$, total precipitable water $(\mathrm{TPW})=5 \mathrm{~mm}$, and $M V I \_B\left(f_{1}, f_{2}\right)^{*}=0.7$.

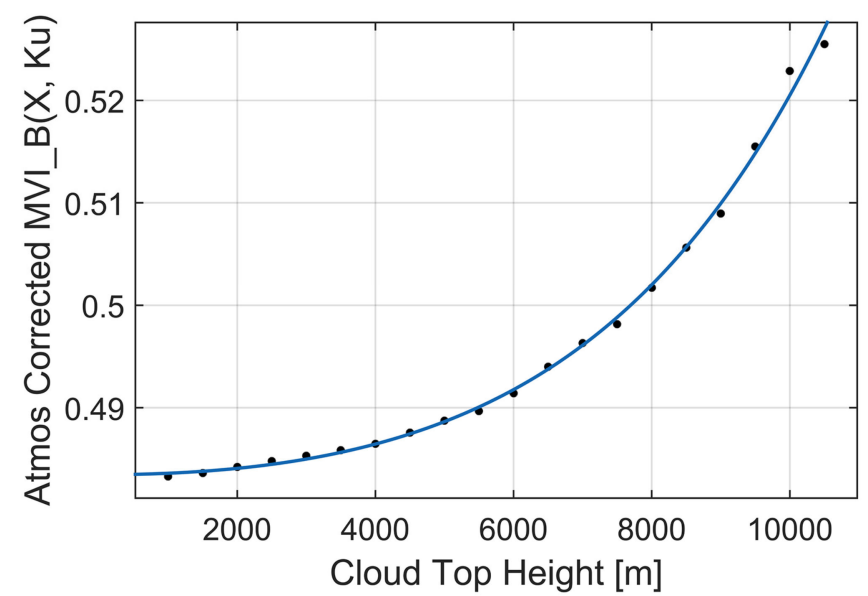

Figure 4. Influence of cloud top height on the atmospheric correction of $M V I \_B(X, K u)$, when surface elevation $=17 \mathrm{~m}, T_{S}=300 \mathrm{~K}$, total precipitable water $(\mathrm{TPW})=25 \mathrm{~mm}$, cloud liquid water $(\mathrm{CLW})=0.1 \mathrm{~mm}$, and $M V I \_B\left(f_{1}, f_{2}\right)^{*}=0.404$. 
According to Equation (6) and as discussed above, when considering water vapor and clouds, the atmosphere-corrected $M V I \_B(X, K u)$ can be expressed as Equation (7).

$$
M V I \_B(X, K u)=M V I \_B(X, K u)^{*} / f\left(T_{s}, T P W, E L E V, C L W, C T H\right)
$$

where ELEV is surface elevation, $\mathrm{CTH}$ is cloud top height. $f\left(T_{S}, T P W, E L E V, C L W, C T H\right)$ is a function of land surface temperature, total precipitable water, surface elevation, cloud liquid water, and $C T H$. If all parameters on the right-hand side of the equation are given, $M V I \_B(X, K u)$ will be retrieved.

The data used to derive all of the parameters on the right-hand side of Equation (7) are easy to obtain from products of AMSR-E and MODIS, both of which are aboard AQUA satellite, and are able to provide almost simultaneous observations at the same location on the Earth surface. $M V I \_B(X, K u)^{*}$ can be directly calculated based on Equation (2) and from brightness temperatures at $10.65 \mathrm{GHz}$ and 18.7 GHz from AMSR-E. When calculating $M V I \_B(X, K u)^{*}$, the invalid values are removed according to the criteria mentioned in Shi et al. [6]. TPW is retrieved from combination of AMSR-E and MODIS using the method in Ji et al. [17]. The surface elevation (ELEV) data is from a combination of SRTM DEM [18] and the MODIS Geolocation product (MOD03/MYD03). As SRTM DEM is only available between the latitudes of $56^{\circ} \mathrm{S}$ and $60^{\circ} \mathrm{N}$, the surface elevation data in the rest of the global area is filled with DEM from MOD03/MYD03. For the overlapping area of SRTM DEM and MOD03/MYD03, the DEM is an arithmetic average combination of the two. CLW can be directly derived from the MODIS cloud product (MYD06) [19,20]. The calculation of CTH is based on the method provided in [21], and the formula is shown in Equation (8):

$$
Z_{C T}=Z_{s f c}+R T_{v(\text { mean })} / g \operatorname{Ln}\left(P_{s f_{c}} / P_{C T}\right)
$$

where $Z_{C T}$ is the cloud top height; $Z_{s f_{c}}$ is the land surface height; $R$ is the gas constant of dry air, and its value is $286.8 \mathrm{Jkg}^{-1} \mathrm{~K}^{-1} ; T_{V(\text { mean })}$ is the mean temperature between the cloud top and land surface; $g$ is gravitational acceleration, and its value is $9.8065 \mathrm{~ms}^{-2} ; P_{s f c}$ is the atmosphere pressure at the ground; $P_{C T}$ is the atmosphere pressure at the cloud top. $T_{V(\text { mean })}, P_{s f_{c}}$, and $P_{C T}$ can be directly obtained from MYD06. However, due to the limitation of the MODIS cloud product algorithm, the MYD06 cloud product is only able to provide CLW and data that is used to calculate CTH during the daytime. Besides MYD06, there is no other source of cloud product that has a simultaneous observation time as AMSR-E at the present. So, the atmospheric correction of $M V I \_B(X, K u)^{*}$ was conducted only with daytime values in this study.

Land surface temperature $T_{S}$ is another variable that is needed in the atmospheric correction according to Equation (7). Figure 5 is an outcome of a simulation which demonstrates the sensitivity of $T_{S}$ to the atmospheric correction of $M V I_{-} B(X, K u)$. According to the figure, an increase of $10 \mathrm{~K}$ in $T_{S}$ will cause a decrease of 0.004 for the atmosphere-corrected $M V I_{-} B(X, K u)$. As the variation range of $T_{S}$ is more than $50 \mathrm{~K}$, the uncertainty of the atmosphere-corrected $M V I \_B(X, K u)$ caused by $T_{S}$ will be greater than 0.02. So, the consideration of $T_{S}$ in Equation (7) will improve the atmospheric correction of $M V I_{-} B(X, K u)$. However, it is not easy to directly obtain $T_{S}$ in all weather conditions. In this study, the $T_{s}$ was derived in four ways. In clear sky conditions, $T_{s}$ was directly derived from the MODIS land surface temperature product [22]. Under cloudy sky conditions, $T_{s}$ was estimated based on the vertical polarized brightness temperature at $36.5 \mathrm{GHz}$ of AMSR-E [23]. The formula is shown in Equation (9):

$$
T_{s}=1.11 T b_{36.5 V}-15.2, \quad \text { where } \quad T b_{36.5 V}>259.8 \mathrm{~K}
$$

where $T b_{36.5 \mathrm{~V}}$ is the AMSR-E vertical polarization brightness temperature at a frequency of $36.5 \mathrm{GHz}$. The error of estimated $T_{s}$ from Equation (9) is approximately $4.5 \mathrm{~K}$. In the area where Equation (9) is not applicable because $T b_{36.5 \mathrm{~V}} \leq 259.8 \mathrm{~K}, T_{s}$ is estimated using an average of the adjacent seven-day land surface temperature derived from the MODIS land surface temperature product. For the areas where $T_{S}$ is still invalid, areas are filled with pixels matching their surrounding pixels. 


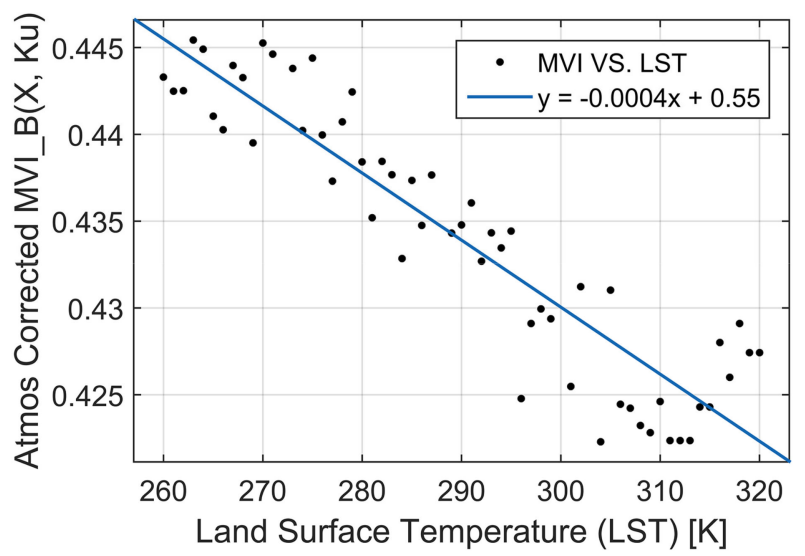

Figure 5. Sensitivity of land surface temperature to the atmospheric correction of $M V I \_B(X, K u)$, when surface elevation $=10 \mathrm{~m}, \mathrm{TPW}=7 \mathrm{~mm}$, cloud top height $(\mathrm{CTH})=3000 \mathrm{~m}, \mathrm{CLW}=0.1 \mathrm{~mm}$ and MVI_B $\left(f_{1}, f_{2}\right)^{*}=0.404$.

Besides the data mentioned above, it is necessary to know the form of the function $f\left(T_{s}, T P W, E L E V, C L W, C T H\right)$ in Equation (7) in order to retrieve the atmosphere-corrected $M V I \_B(X, K u)$. However, it is not easy to obtain an exact form for the function due to the complex relationship of the parameters in the function. As a matter of convenience, a reference table is built-in to retrieve the atmosphere-corrected $M V I \_B(X, K u)$. If ELEV, $T_{s}, T P W, C T H, C L W$, and $M V I \_B(X, K u)^{*}$ are given, the atmosphere corrected $M V I_{-} B(X, K u)$ can be directly calculated according to the reference table. The main steps of retrieving the atmosphere-corrected $M V I \_B(X, K u)$ are described as follows:

(1) Data pre-processing. All the related remote sensing data were projected into $0.25^{\circ} \times 0.25^{\circ}$ grid images. The data included AMSR-E brightness temperature, MODIS cloud product (MYD06), MODIS land surface product (MYD11), MODIS geolocation product (MYD03), and SRTM DEM.

(2) Preparation of data for atmospheric correction. The data required in the atmosphere correction included $M V I_{-} B(X, K u)^{*}$, ELEV, $T_{s}, T P W, C T H$, and CLW. The methods for calculating these parameters are mentioned above within this section.

(3) Construction of a reference table for atmospheric correction. The reference table was built using cloud profiles, atmospheric profiles, and the Model 1DMWRTM. The cloud profiles only included a single-layer cloud, and these were created according to the amount of cloud liquid water and cloud top height. The atmospheric profiles were selected from globally distributed radiosonde observations (RAOB) according to surface elevation, land surface temperature, and the total precipitable water of a profile. There were seven fields in the reference table, which included ELEV, $T_{s}, \mathrm{TPW}, \mathrm{CTH}, \mathrm{CLW}, M V I \_B(X, K u)$, and $M V I \_B(X, K u)^{*}$. For the circumstance of clear sky conditions, both CTH and CLW were set to 0 in the reference table.

(4) Atmospheric correction and post-processing. In order to retrieve the atmosphere-corrected $M V I \_B(X, K u)$ conveniently, a reference table was used. The reference table was built in Step (3), and the input parameters were obtained in Step (2). As the valid range of $M V I \_B(X, K u)$ was between 0 and 1 , values out of this range would be masked and filled with their surrounding values.

\section{Results and Uncertainty Analysis}

A daily global coverage of atmosphere-corrected $M V I \_B(X, K u)$ in ascending orbit for the year of 2007 was retrieved using the method mentioned above. As it was difficult to acquire accurate measurements for $M V I \_B(X, K u)$ using a $0.25^{\circ} \times 0.25^{\circ}$ grid from the field experiment, it was difficult for us to quantitatively validate the accuracy of atmosphere-corrected $M V I \_B(X, K u)$ using ground measurements. As alternatives, qualitative validations in temporal and spatial scales were used in this 
study. In addition, uncertainty analysis using simulated data was also conducted to further verify the precision of the atmospheric correction algorithm.

In most areas of the earth, the atmosphere has obvious seasonal changes, which will make differences between $M V I \_B(X, K u)^{*}$ (the original MVI) and $M V I \_B(X, K u)$ (the atmosphere-corrected MVI) affected by seasonal changes. It is possible to qualitatively confirm the validity of atmosphere correction for $M V I \_B$ by comparing the time series between $M V I \_B(X, K u)^{*}$ and $M V I \_B(X, K u)$. As a qualitative validation in temporal scale, the time series between $M V I_{-} B(X, K u)^{*}$ and $M V I \_B(X, K u)$ in a year scale were compared with each other on various land surface types. There were 12 selected points in the validation, and the distribution of them is shown in Figure 6. Each point represented a kind of land surface type. The land surface type and position of the selected validation points are listed in Table 1.

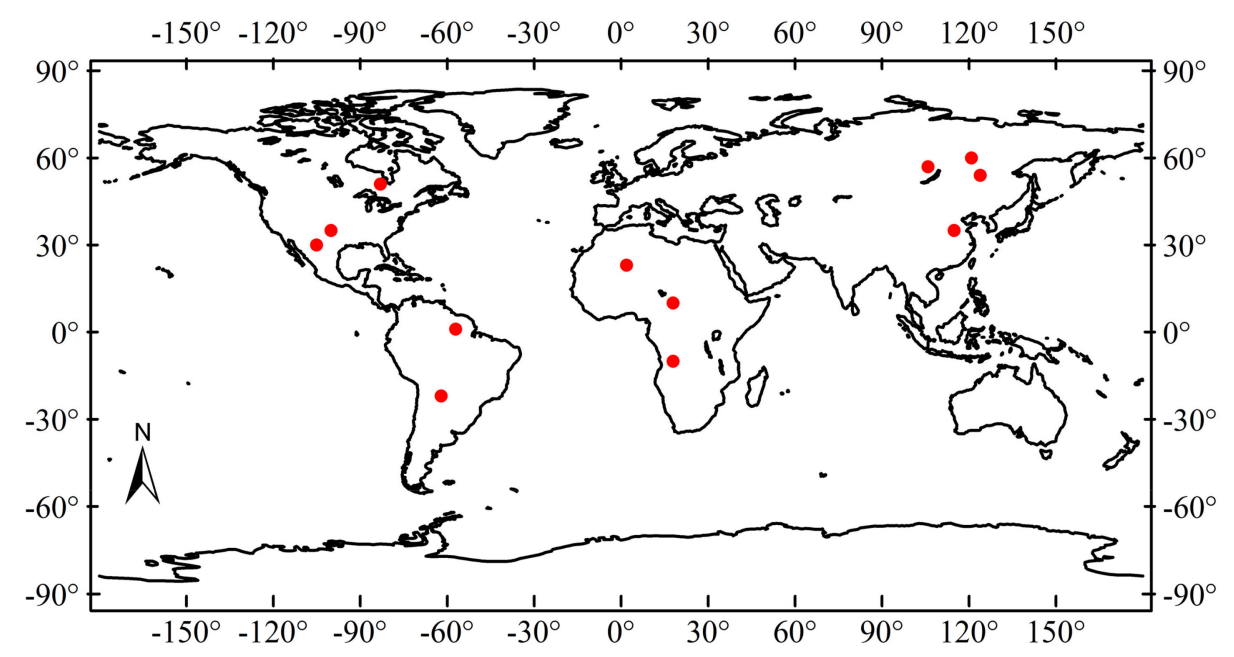

Figure 6. Distribution of selected validation points on global scale.

Table 1. Land surface type and position of the selected validation points.

\begin{tabular}{ccc}
\hline Number & Land Surface Type & Position (Lat., Long.) \\
\hline 1 & Evergreen Needleleaf Forest & $\left(54^{\circ}, 124^{\circ}\right)$ \\
2 & Evergreen Broadleaf Forest & $\left(1^{\circ},-57^{\circ}\right)$ \\
3 & Deciduous Needleleaf Forest & $\left(60^{\circ}, 121^{\circ}\right)$ \\
4 & Deciduous Broadleaf Forest & $\left(-22^{\circ},-62^{\circ}\right)$ \\
5 & Mixed Forests & $\left(57^{\circ}, 106^{\circ}\right)$ \\
6 & Open Shrublands & $\left(30^{\circ},-105^{\circ}\right)$ \\
7 & Woody Savannas & $\left(-10^{\circ}, 18^{\circ}\right)$ \\
8 & Savannas & $\left(10^{\circ}, 18^{\circ}\right)$ \\
9 & Grasslands & $\left(35^{\circ},-100^{\circ}\right)$ \\
10 & Permanent Wetlands & $\left(51^{\circ},-83^{\circ}\right)$ \\
11 & Croplands & $\left(35^{\circ}, 115^{\circ}\right)$ \\
12 & Barren or Sparsely Vegetated & $\left(23^{\circ}, 2^{\circ}\right)$ \\
\hline
\end{tabular}

Figure 7 shows the comparison of time series between $M V I \_B(X, K u)^{*}$ and $M V I \_B(X, K u)$ on 12 land surface types. In the figure, the red solid line with an asterisk represents the time series of $M V I \_B(X, K u)^{*}$ which represented the original MVI without atmospheric correction; while the blue solid line represents time series of $M V I \_B(X, K u)$ which represented the atmosphere-corrected MVI. As the creation of the time series was based on daily MVI, there were many high-frequency fluctuations in the time series, which may bring disturbances to the analysis of trends in the MVI time series. In order to clearly reveal seasonal variations for $M V I \_B(X, K u)^{*}$ and $M V I \_B(X, K u)$, a low pass filter function was applied to the time series of both $M V I_{-} B(X, K u)^{*}$ and $M V I_{-} B(X, K u)$ to remove the 
high frequency fluctuations. Three conclusions were drawn from the comparison of the time series between $M V I \_B(X, K u)^{*}$ and $M V I \_B(X, K u)$.

(1) The existence of atmosphere will obviously lower the value of $M V I \_B$. As the value of $M V I \_B$ is negatively related with the density of vegetation, if the $M V I \_B$ was directly used in the retrieval of optical thickness and biomass of vegetation, it would cause a significant overestimation. It is therefore necessary to make an atmospheric correction before the $M V I \_B$ is further applied.

(2) The difference between $M V I_{-} B(X, K u)^{*}$ and $M V I \_B(X, K u)$ caused by the atmosphere shows obvious seasonal variation on most land surfaces, except for deciduous needleleaf forest and mixed forests, as shown in Figure 7c,e, respectively. As is shown in Figure 7a,b,f-l, the difference between $M V I \_B(X, K u)^{*}$ and $M V I \_B(X, K u)$ in the summer season was larger than in the winter season. The reason for this phenomenon is that there is more water vapor and more clouds in the atmosphere during the summer season of the northern hemisphere. The increment of water vapor and clouds would decrease the value of $M V I \_B$. The difference between $M V I \_B(X, K u)^{*}$ and $M V I \_B(X, K u)$ in Figure 7d,g showed different seasonal variation with that in others sub-figures, the reason is that the selected two land surface types are located in the southern hemisphere, which has an opposite trend of seasonal variation compared to the northern hemisphere. The reason for the low contrast between $M V I \_B(X, K u)^{*}$ and $M V I \_B(X, K u)$ in Figure 7c,e may be attributed to low cloud liquid water and water vapor content in the high latitude areas, and the atmospheric correction method was not sensitive to such a low amount of water in the atmosphere. On the whole, the seasonal variation of the difference between $M V I \_B(X, K u)^{*}$ and $M V I \_B(X, K u)$ on most of the land surface types confirmed that the atmospheric correction algorithm was effective in reducing the influence of water vapor and clouds.

(3) For the land surface types with rare vegetation cover, such as barren or sparsely vegetated and open shrublands, the time series of $M V I \_B$ should not have had any obvious seasonal variation. However, there were obvious low values of $M V I \_B(X, K u)^{*}$ in the summer season on barren or sparsely vegetated and open shrubland areas, as shown by the red solid line with an asterisk in Figure 7f,1. The low values were mainly caused by the increment of water vapor and clouds in the summer season. As a comparison, there were no obvious seasonal changes in the time series of $M V I \_B(X, K u)$ according to the blue solid lines in Figure $7 f, 1$, which means that the underestimation of $M V I \_B(X, K u)^{*}$ in the summer season could be improved by applying atmospheric correction.

According to the time series comparisons mentioned above, the atmospheric correction could improve the underestimation of $M V I \_B$ and make the changing trend of $M V I \_B$ time series more reasonable on various land surface types. As the time series comparisons were only performed at limited validation points around the globe, it still needs more comparisons on a spatial scale in order to validate the effectiveness of atmospheric correction on $M V I \_B$.

Figure 8 shows a comparison between $M V I \_B(X, K u)^{*}$ (original $\left.M V I \_B\right)$ and $M V I \_B(X, K u)$ (atmosphere-corrected $M V I \_B$ ) on a spatial scale. The left two figures (Figures 8a and 8c) are of the original MVI_B without atmospheric correction. The data in Figure 8a is created from an average of daily MVI_B in the months of December, January and February (DJF), and the data in Figure 8c is created from an average of daily $M V I \_B$ in the months of June, July and August (JJA). The right two figures Figures $8 \mathrm{~b}$ and $8 \mathrm{~d}$ are atmosphere-corrected $M V I \_B$ that correspond to Figures 8a and 8c respectively. The data in the four figures in Figure 8 is colored using same density slicing criteria and color table to ensure that the four figures are evaluated under same conditions. 


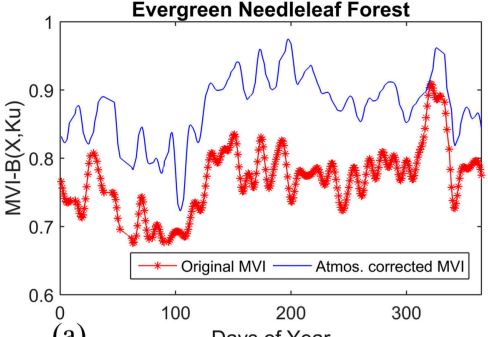

(a)

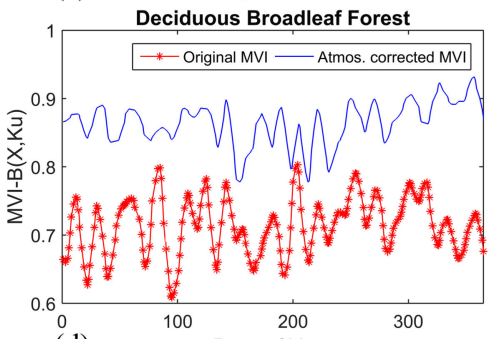

(d)
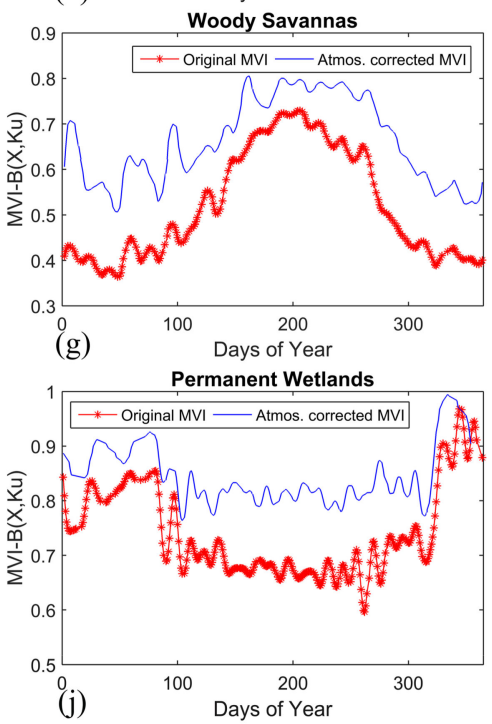

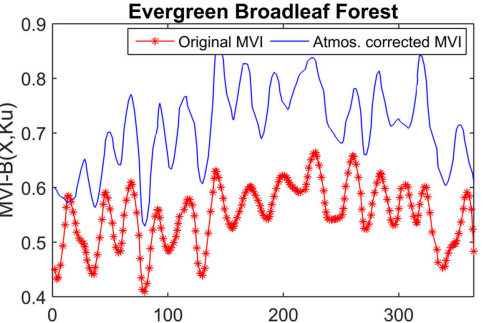

(b)

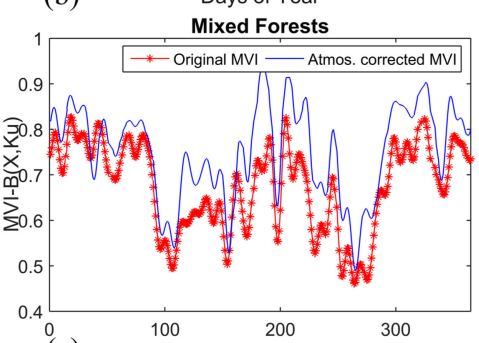

(e)
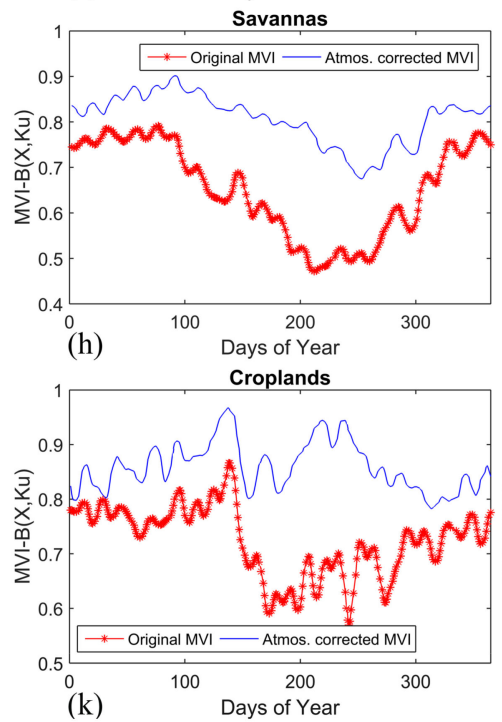

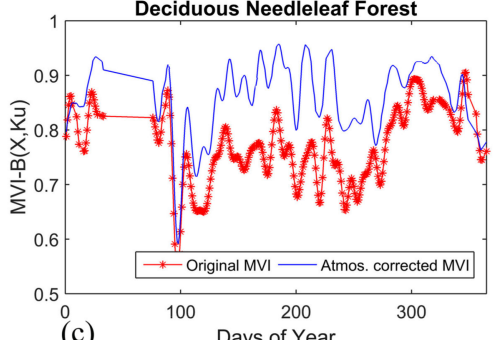

(c)

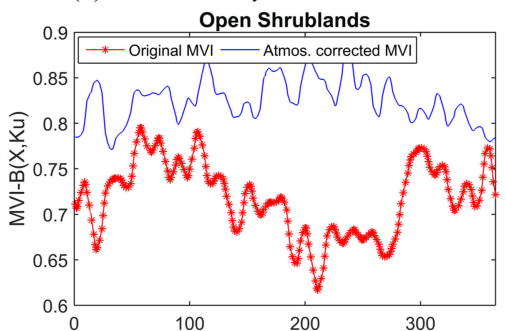

(f)

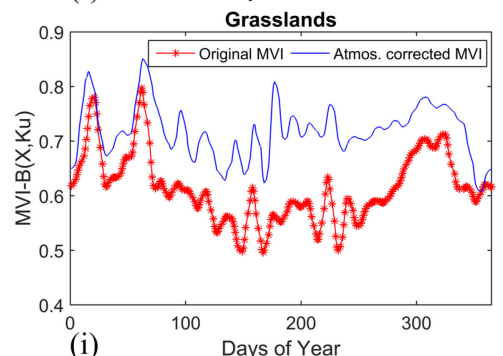

(i) Days of Year

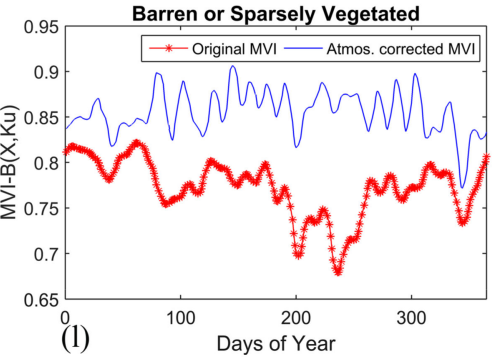

Figure 7. Time series comparison between $M V I \_B(X, K u)^{*}$ [original microwave vegetation index (MVI)] and $M V I \_B(X, K u)$ (atmosphere corrected MVI) on various land surface types. (a) Time series comparison between $M V I_{-} B(X, K u)^{*}$ and $M V I_{-} B(X, K u)$ on Evergreen Needleleaf Forest; (b) Time series comparison between $M V I_{-} B(X, K u)^{*}$ and $M V I \_B(X, K u)$ on Evergreen Broadleaf Forest; (c) Time series comparison between $M V I \_B(X, K u)^{*}$ and $M V I \_B(X, K u)$ on Deciduous Needleleaf Forest; (d) Time series comparison between $M V I \_B(X, K u)^{*}$ and $M V I \_B(X, K u)$ on Deciduous Broadleaf Forest; (e) Time series comparison between $M V I \_B(X, K u)^{*}$ and $M V I \_B(X, K u)$ on Mixed Forest; (f) Time series comparison between $M V I_{-} B(X, K u)^{*}$ and $M V I \_B(X, K u)$ on Open Shrublands; (g) Time series comparison between $M V I \_B(X, K u)^{*}$ and $M V I \_B(X, K u)$ on Woody Savannas; (h) Time series comparison between $M V I \_B(X, K u)^{*}$ and $M V I \_B(X, K u)$ on Savannas; (i) Time series comparison between $M V I \_B(X, K u)^{*}$ and $M V I \_B(X, K u)$ on Grasslands; (j) Time series comparison between $M V I \_B(X, K u)^{*}$ and $M V I \_B(X, K u)$ on Permanent Wetlands; (k) Time series comparison between $M V I \_B(X, K u)^{*}$ and $M V I \_B(X, K u)$ on Croplands; (1) Time series comparison between $M V I \_B(X, K u)^{*}$ and $M V I \_B(X, K u)$ on Barren or Sparsely Vegetated.

As is shown by the comparison between Figures $8 a$ and $8 b$, the two figures had very little differences in the northern part of North America and Eurasia. The reason is that there is a small amount of water vapor and cloud liquid water in the winter season of the high latitudes of the northern hemisphere. While the difference of the two figures became larger in the middle and low latitudes, 
especially in the southern hemisphere, such as at the Amazon River Basin, the Sahara Desert, and the middle of Africa and Australia, the reason was that there is abundant water vapor and cloud liquid water in atmospheres of low latitudes located in the southern hemisphere. Figure 8c,d shows the comparison of $M V I_{-} B(X, K u)^{*}$ and $M V I_{-} B(X, K u)$ in the months of JJA which are during the summer season in the northern hemisphere. According to the comparison of the two figures, the influence of atmosphere was obvious in almost all parts of the global land surface. Especially in the high latitudes of the northern hemisphere, the influence of atmosphere was more serious than that shown in Figure 8a,b, the reason being that the northern hemisphere was in the summer season and had abundant water vapor and cloud liquid water. According to the comparison between the left two figures and the right two figures in Figure 8, the atmospheric correction improved the underestimation of $M V I \_B$ in both winter and summer seasons, and the contrast between barren and vegetated areas was more obvious after atmospheric correction. For example, the values of $M V I \_B$ in the Sahara Desert and in center part of Oceania were closer to 1 after atmospheric correction. However, there were several regions that had abnormal values, such as in the southern region of China and in India, as shown in Figure 8d, and in the area around the Amazon river, as shown in Figure $8 \mathrm{~b}$, d, where all the three regions are covered with dense vegetation. The abnormal values may be attributed to the limitation of the microwave vegetation index which has been discussed in Shi et al. [6]. The paper states that "the MVI will have a non-unique relationship in regions where the sensor can 'see' the ground surface at both frequencies and the regions where the sensor cannot 'see' ground surface at one or both frequencies, the $B$ parameters derived from the bare surface could have a similar magnitude as that derived from a dense forest with the fraction cover $F_{v}<1$ ". The abnormal value was more obvious in Figure 8b,d than in Figure 8a,c. The reason for this was that the data in Figure 8a,c was influenced by water vapor and cloud liquid water.

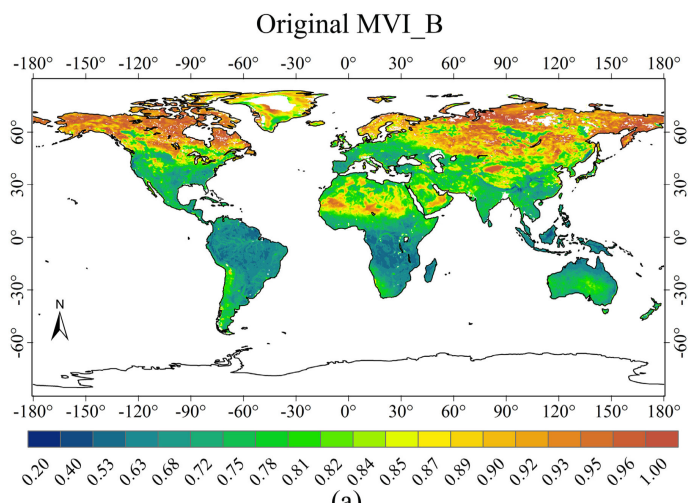

(a)

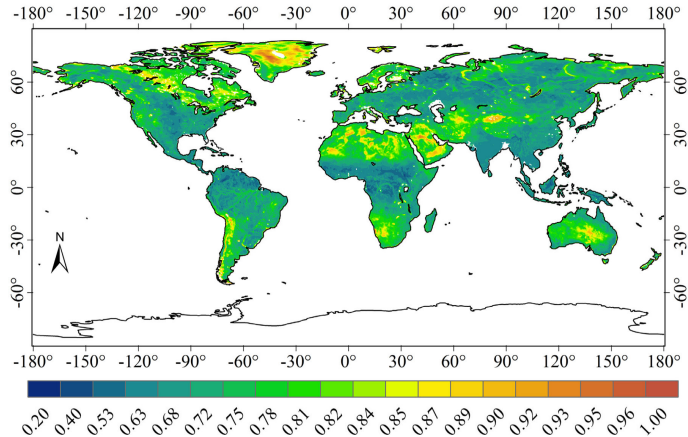

(c)
Atmosphere Corrected MVI_B

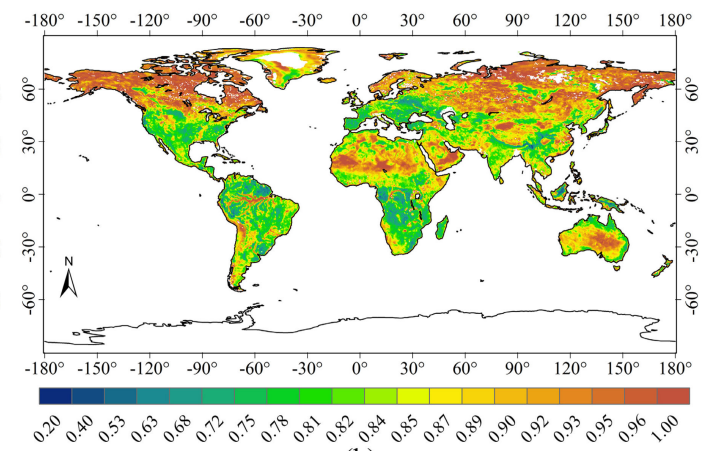

(b)

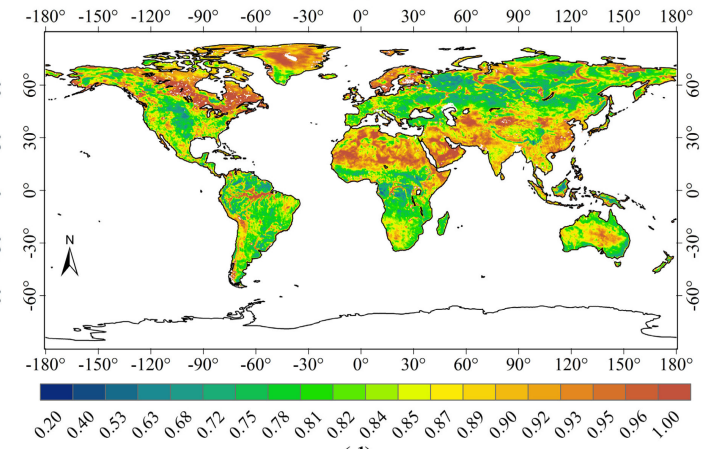

(d)

Figure 8. Comparison between $M V I \_B(X, K u)^{*}$ (original $\left.M V I \_B\right)$ and $M V I \_B(X, K u)$ (atmosphere corrected $M V I \_B$ ) on a spatial scale; (a) Seasonal average of original $M V I \_B$ in the months of December, January and February (DJF); (b) Seasonal average of $M V I \_B$ after atmospheric correction in the months of DJF; (c) Seasonal average of original MVI_B in the month of June, July and August (JJA); (d) Seasonal average of $M V I \_B$ after atmospheric correction in the months of JJA. 
Seasonal averaged NDVI derived from MODIS was also used to further examine the result of atmospheric correction, as shown in Figure 8. Figure 9 shows global distribution map of seasonal averaged NDVI derived from MODIS. Figure 9a shows seasonal averaged NDVI during the winter season of the northern hemisphere (DJF); Figure $9 \mathrm{~b}$ shows seasonal averaged NDVI during summer season of the northern hemisphere (JJA). During the winter season of the northern hemisphere, it can be seen from the comparison among Figure 8a,b, and Figure 9a, that Figure $8 b$ showed a higher similarity with Figure 9a than Figure 8a, especially in the area of Oceania and in the northern part of Africa. Figure $8 \mathrm{c}, \mathrm{d}$ and Figure $9 \mathrm{~b}$ show a comparison between $M V I \_B$ and NDVI during the summer season of the northern hemisphere; according to the comparison, Figure $8 \mathrm{~d}$ showed higher similarity with Figure $9 \mathrm{~b}$ than with Figure 8c. For example, as is shown in Figure 8d, there was an obvious vegetation coverage belt in the northern part of Eurasia, and an arid belt in the middle part of Eurasia and in the northern part of Africa. This great contrast of vegetation coverage in the region of Eurasia and in the northern part of Africa was also evident in Figure 9b, but was not obvious in Figure 8c. According to the comparison between Figures 8 and 9, the atmosphere-corrected MVI_B showed a higher similarity with NDVI in spatial distribution than the original MVI_B with NDVI, which means the atmospheric correction algorithm developed in this study improved the ability of $M V I \_B$ to monitor global vegetation.

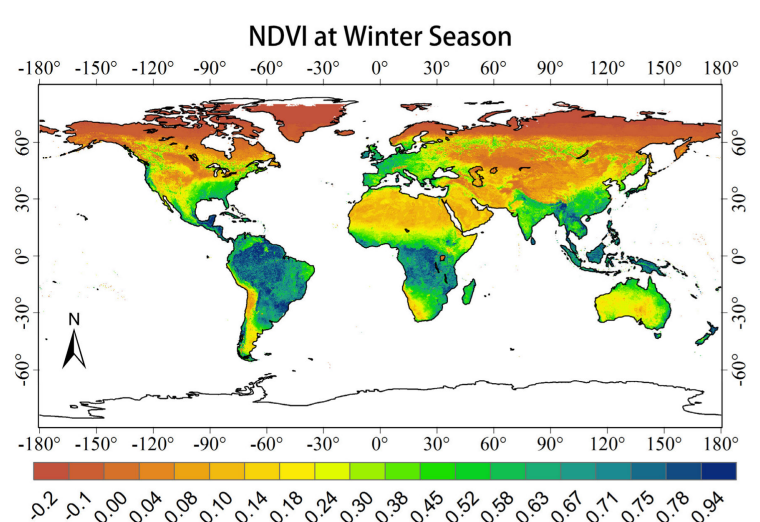

(a)

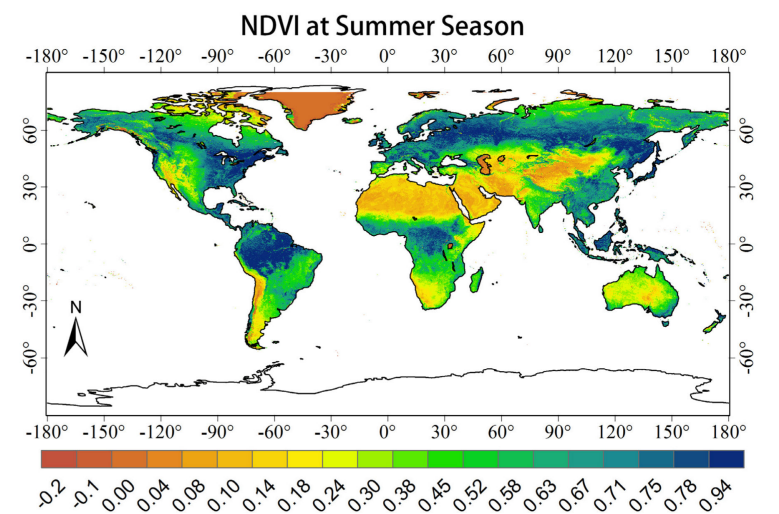

(b)

Figure 9. Global distribution map of seasonal averaged NDVI from MODIS; (a) Seasonal averaged NDVI during the winter season of the northern hemisphere (DJF); (b) Seasonal averaged NDVI during the summer season of the northern hemisphere (JJA).

It is necessary to discuss the uncertainties in the atmospheric correction algorithm. As is discussed in Section 2.2 and according to Equation (7), land surface temperature, total precipitable water, surface elevation, cloud liquid water and cloud top height are the key parameters that influence the atmospheric correction of $M V I \_B$. The uncertainties of these parameters will finally have an impact on the accuracy of the atmospheric-corrected $M V I \_B$. Water vapor and clouds are two main constituents in the atmosphere that influenced the atmospheric correction on $M V I_{-} B$. The accuracy of total precipitable water in all-weather condition over land is about $3.5 \mathrm{~mm}$ [17]; and the precision of cloud top height is about $1.5 \mathrm{~km}$ [21]; for the cloud liquid water from MODIS cloud product (MYD06), its accuracy is about $0.041 \mathrm{~mm}$ according to comparisons with cloud liquid water from AMSR-E [24]. For the land surface parameters, the accuracy of surface temperature and surface elevation will also have an influence on the atmospheric-corrected MVI_B. According to the validation in the paper [23], the accuracy of land surface temperature estimated using Equation (9) is about $4.5 \mathrm{~K}$. Surface elevation used in this study was a combination of SRTM DEM and DEM from MYD03. The accuracy of SRTM DEM is less than $10 \mathrm{~m}$ [25], and the DEM from MYD03 is expected to have, at worst, $100 \mathrm{~m}$ uncertainty in the vertical direction [26]. In order to analyze how error these input parameters would transfer to the atmosphere-corrected $M V I \_B$, a series of simulations were carried 
out in the atmospheric-correction, and the outcomes are shown in Figure 10. From analysis of the influence of uncertainty of TPW on the atmosphere-corrected $M V I \_B$, a reference atmosphere-corrected $M V I \_B(\mathrm{X}, \mathrm{Ku})$ was first calculated using the method mentioned in Section 2.3, then a TPW error matrix was created from a normal (Gaussian) distribution with a mean of zero and a standard deviation of $3.5 \mathrm{~mm}$, and the TPW error matrix was added to the input parameter TPW in the atmosphere correction to obtain a new atmosphere-corrected $M V I \_B(\mathrm{X}, \mathrm{Ku})$ with a TPW error. The difference between the new atmosphere-corrected $M V I \_B(\mathrm{X}, \mathrm{Ku})$ with a TPW error and the reference atmosphere corrected $M V I \_B(\mathrm{X}, \mathrm{Ku})$ demonstrated the error of the atmosphere-corrected $M V I \_B(\mathrm{X}, \mathrm{Ku})$ caused by the uncertainty of TPW, and the histogram of the difference is shown in Figure 10a. According to the Figure, the RMSE between the reference atmosphere corrected $M V I \_B(\mathrm{X}, \mathrm{Ku})$ and the new atmosphere corrected MVI_B(X, Ku) with TPW error was 0.0233 , and $78.46 \%$ of the difference was in the range of $[-0.0233,0.0233]$. For the uncertainty of CLW, CT, Ts, and DEM, the analysis of their influence on the atmospheric correction of $M V I \_B$ was same as that of the uncertainty of TPW. In each analysis, the error matrix created from a normal (Gaussian) distribution with a mean of zero and a standard deviation of $0.041 \mathrm{~mm}, 1.5 \mathrm{~km}, 4.5 \mathrm{~K}$ and $50 \mathrm{~m}$ was added to the input parameters CLW, CT, Ts, and DEM, respectively, to obtain new atmosphere corrected $M V I \_B(\mathrm{X}, \mathrm{Ku})$ with error. Each new atmosphere-corrected $M V I \_B(\mathrm{X}, \mathrm{Ku})$ with CLW, CT, Ts and DEM error was used respectively to calculate the difference from the reference atmosphere-corrected $M V I \_B(\mathrm{X}, \mathrm{Ku})$, and the outcomes are shown in Figure 10b-e, respectively. According to these figures, for clouds, an uncertainty of $0.041 \mathrm{~mm}$ in CLW and $1.5 \mathrm{kn}$ in CT would cause an error of 0.01 and 0.013 , respectively, in the atmosphere-corrected $M V I \_B(\mathrm{X}, \mathrm{Ku})$; for surface boundary parameters, an uncertainty of $4.5 \mathrm{~K}$ in surface temperature, and $50 \mathrm{~m}$ in DEM would cause an error of 0.0177 and 0.0141 , respectively, in the atmosphere-corrected $M V I \_B(\mathrm{X}, \mathrm{Ku})$. When considering the uncertainties of all the input parameters together in the atmospheric correction, the RMSE between the reference atmosphere-corrected $M V I \_B(\mathrm{X}, \mathrm{Ku})$ and the new atmosphere-corrected $M V I \_B(\mathrm{X}, \mathrm{Ku})$ with all errors was 0.0335 , and $81.37 \%$ of the difference was in the range of $[-0.0355,0.0355]$, with the outcome is shown in Figure $10 \mathrm{f}$. According to the comparison in Figure 10, the uncertainty of TPW had the greatest influence on the atmosphere corrected $M V I \_B(\mathrm{X}, \mathrm{Ku})$, which may be attributed to the difficulty of retrieving high precision TPW over the land using microwave radiometer in cloudy sky conditions.

When considering the difference between the atmosphere-corrected $M V I B B(\mathrm{X}, \mathrm{Ku})$ and the original $M V I \_B(\mathrm{X}, \mathrm{Ku})$, a value of the difference being less than or equal to 0.0335 meant that the effect of atmosphere correction was not significant. In order to analyze the distribution of the insignificant area of atmospheric correction, the difference between the atmosphere-corrected $M V I \_B(\mathrm{X}, \mathrm{Ku})$ and the original MVI_B(X, Ku) was calculated based on the data shown in Figure 8, and the outcomes were shown in Figure 11. The data shown in Figure 11a was the difference between seasonal averaged $M V I \_B(X, K u)$ and $M V I \_B(X, K u)^{*}$ in the months of DJF, which was calculated using the data in Figure $8 \mathrm{~b}$ minus the data in Figure $8 \mathrm{a}$. Figure $11 \mathrm{~b}$ shows the difference between seasonal averaged $M V I \_B(X, K u)$ and $M V I \_B(X, K u)^{*}$ in the months of JJA, and the difference was derived using the data in Figure $8 \mathrm{~d}$ minus the data in Figure 8c. In both images within Figure 11, the pixels that are less than or equal to 0.0335 are marked as gray, and the area in gray represented a non-significant effect from atmospheric correction. According to the statistics from the two images in Figure 11, 31.4\% pixels were marked as gray in Figure 11a, and most of the pixels in gray were distributed within high latitudes of the northern hemisphere. The reason for this is that water vapor or liquid water in clouds are much lower in the atmosphere in the winter of the northern hemisphere, and the influence of the atmosphere was thus not significant in calculating MVI. In contrast, in Figure 11b, only $0.7 \%$ of pixels were marked as gray, and most of the pixels were located in Greenland. The reason for this is that water vapor and cloud liquid water become abundant in the summer of the northern hemisphere. In summary, the insignificant area of atmospheric correction depends on the water vapor and cloud liquid water content in the atmosphere. If the water vapor and cloud liquid water in the atmosphere is small, it is not necessary to perform an atmospheric correction for MVI. 


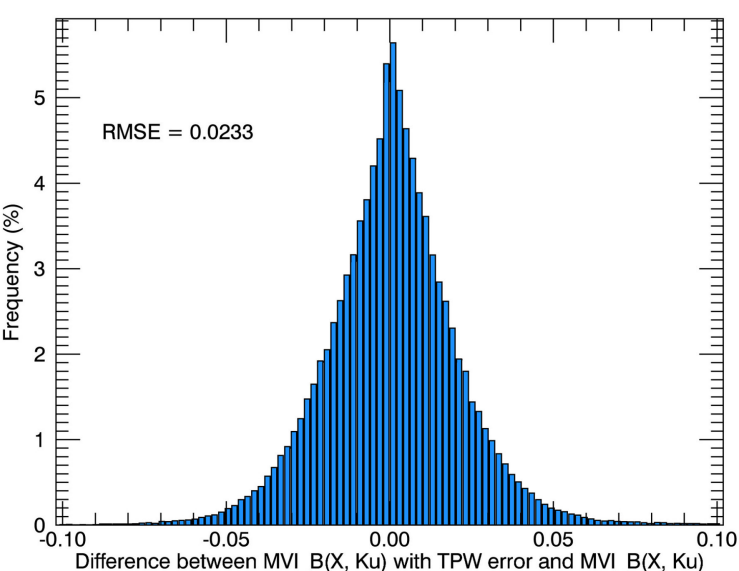

(a)

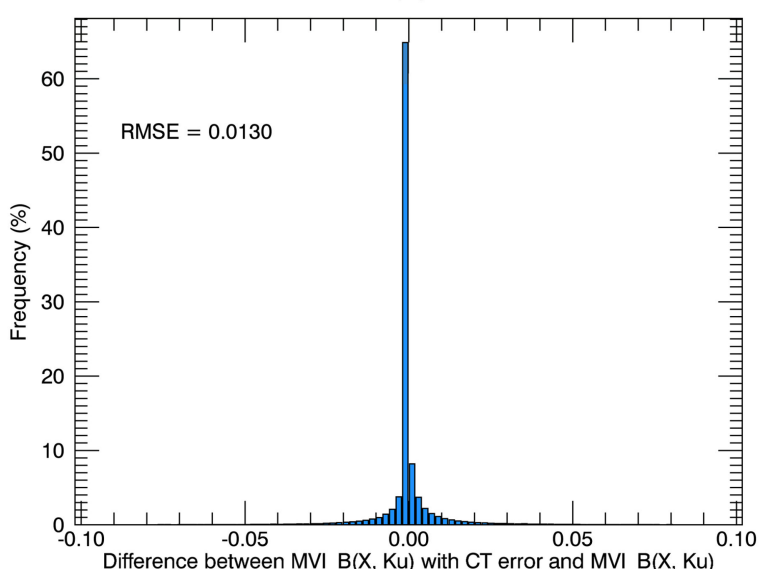

(c)

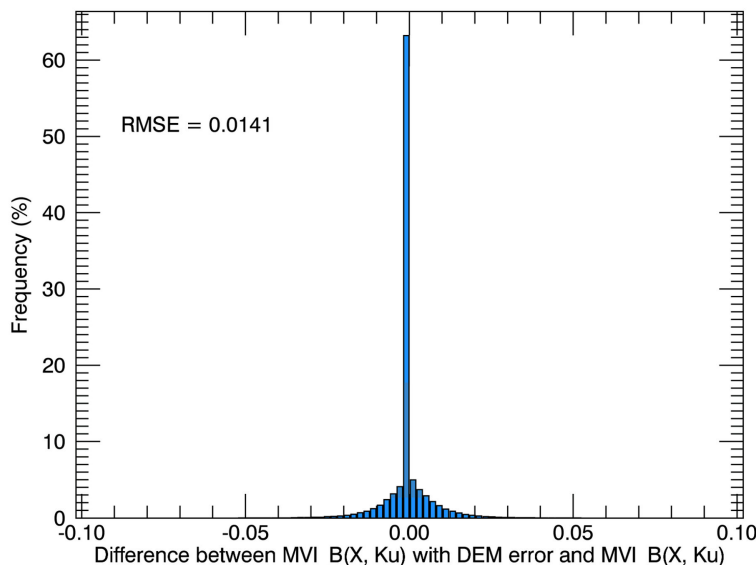

(e)

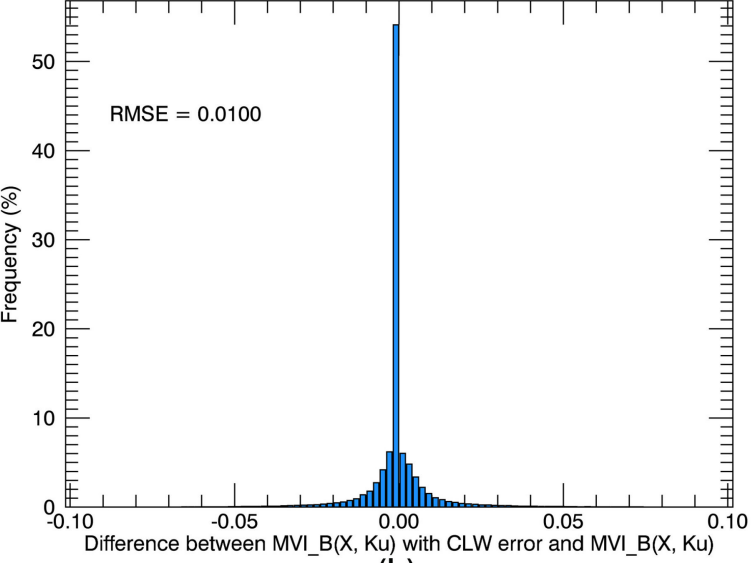

(b)

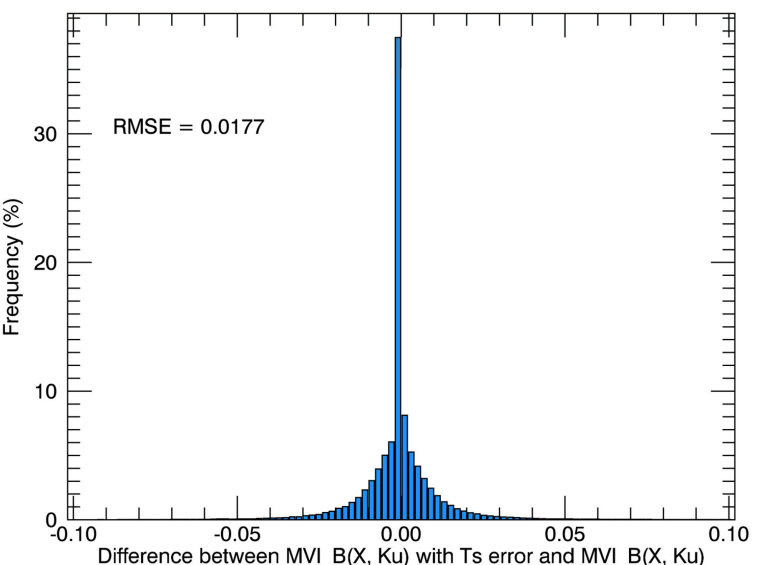

(d)

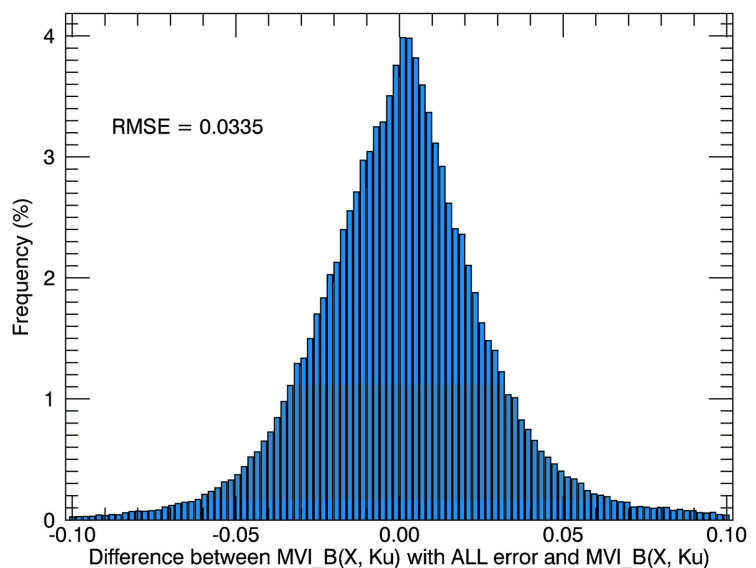

(f)

Figure 10. $M V I \_B(\mathrm{X}, \mathrm{Ku})$ error analysis caused by the uncertainty of input parameters in the atmospheric correction; (a) Difference between $M V I \_B(\mathrm{X}, \mathrm{Ku})$ with TPW error and $M V I \_B(\mathrm{X}, \mathrm{Ku})$; (b) Difference between $M V I \_B(\mathrm{X}, \mathrm{Ku})$ with $C L W$ error and $M V I \_B(\mathrm{X}, \mathrm{Ku})$; (c) Difference between $M V I \_B(\mathrm{X}, \mathrm{Ku})$ with $C T$ error and $M V I \_B(\mathrm{X}, \mathrm{Ku}) ;(\mathbf{d})$ Difference between $M V I \_B(\mathrm{X}, \mathrm{Ku})$ with $T$ s error and $M V I \_B(\mathrm{X}, \mathrm{Ku}) ;(\mathbf{e})$ Difference between $M V I \_B(\mathrm{X}, \mathrm{Ku})$ with DEM error and $M V I \_B(\mathrm{X}, \mathrm{Ku})$; (f) Difference between $M V I \_B(\mathrm{X}, \mathrm{Ku})$ with all parameter errors and $M V I \_B(\mathrm{X}, \mathrm{Ku})$. 


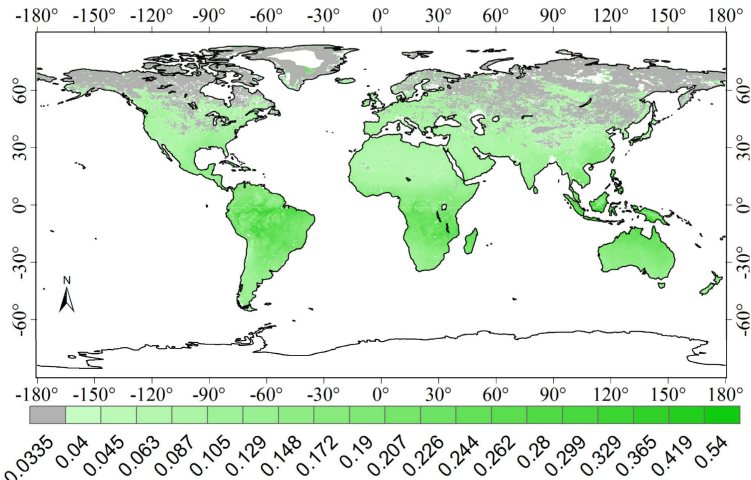

(a)

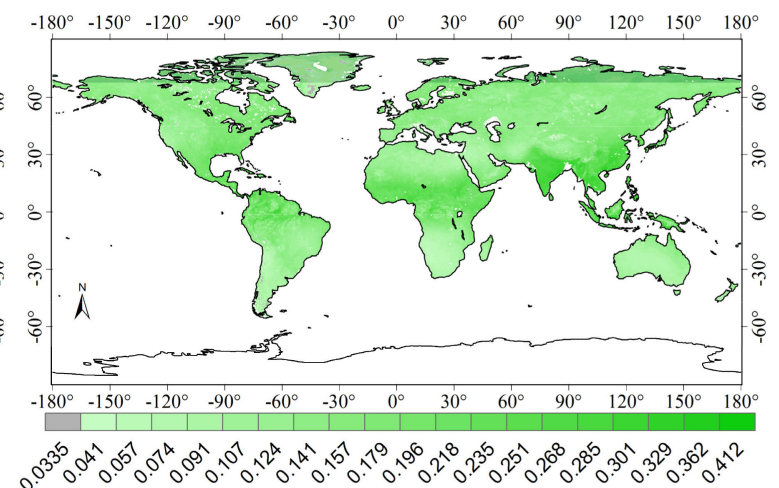

(b)

Figure 11. The difference between seasonal averaged $M V I \_B(X, K u)$ (atmosphere corrected $M V I \_B$ ) and $M V I \_B(X, K u)^{*}$ (original $\left.M V I \_B\right)$; (a) The difference between seasonal averaged $M V I \_B(X, K u)$ and $M V I \_B(X, K u)^{*}$ in the months of DJF; $(\mathbf{b})$ the difference between seasonal averaged $M V I \_B(X, K u)$ and $M V I \_B(X, K u)^{*}$ in the months of JJA.

\section{Conclusions}

In this study, we analyzed the influence of the atmosphere on the observation of MVI, and developed an atmospheric correction algorithm for MVI using observations from AMSR-E and MODIS. According to the sensitivity analysis, the influence of atmosphere on the MVI was mainly caused by water vapor and clouds in the atmosphere. The degree of influence was frequency-dependent. For the $M V I \_B$ at high frequencies $M V I_{-} B(X, K u)$, both water vapor and cloud liquid water had obvious influences on this value. For $M V I \_B$ at low frequencies $M V I \_B(C, X)$, both cloud liquid water and water vapor had a smaller effect than on that of $M V I \_B(\mathrm{X}, \mathrm{Ku})$. Therefore, only atmospheric correction for $M V I \_B(\mathrm{X}, \mathrm{Ku})$ was discussed in this study. Based on the sensitivity analysis, an atmospheric correction algorithm was developed using reference table technology. As a validation, the original MVI_B and the atmospheric corrected $M V I \_B$ were compared at both temporal and spatial scales. Compared to the original $M V I \_B$, the improvements of atmospheric correction for $M V I \_B$ are summarized as follows:

(1) Atmospheric correction can greatly improve the underestimation of $M V I \_B$. The difference between the original MVI_B and the atmosphere-corrected $M V I \_B$ can reach up to 0.3 according to the data shown in Figure 7.

(2) The atmospheric correction can make the seasonal variation of $M V I \_B$ more reasonable. For barren or sparsely vegetated areas, the value of original MVI_B will decrease in the summer season due to the influence of increasing water vapor and clouds in atmosphere. The atmosphere correction can correct the decreasing trends of $M V I \_B$ in this type of land surface. In addition, the difference between the original MVI_B and atmosphere-corrected $M V I \_B$ in winter is smaller than that in summer, which further confirms that the influence of atmosphere has seasonal differences, and also demonstrate the effectiveness of atmospheric correction.

(3) On a spatial scale, the influence of atmosphere in low latitudes is higher than that of high latitudes. The underestimation of $M V I \_B$ in barren or less-vegetated areas in low latitudes can be improved by atmospheric correction, and thus further enhance the contrast between barren areas and vegetated areas.

Overall, atmospheric correction will make MVI_B more reliable, and enhance its ability to monitor vegetation information and calculate vegetation biomass at regional or global scales, and further extend the application of microwaves for the study of global carbon cycles and the Earth's ecosystem.

Due to the limitation of our knowledge about precipitation, the influence of precipitation on MVI and the related precipitation correction algorithm for MVI was not discussed in this study. In addition, water vapor and clouds are two main constituents in the atmosphere that influence the atmospheric 
correction of $M V I \_B$. According to the uncertainty analysis, the uncertainty of TPW contributes a large part to the error of the atmosphere-corrected $M V I \_B$. This can be attributed to the difficulty in retrieving TPW during cloudy conditions over land. Although the TPW over land, retrieved using the method of Ji [17], is clearly improved compared with previous studies, it needs further improvement when used in atmospheric correction, in order to obtain a higher precision MVI_B. For clouds, under the conditions of multi-layer and thick clouds, cloud liquid water derived from MODIS cloud product is also a large error source for the atmospheric correction algorithm, as the optical sensor cannot see through clouds. The development of the atmospheric correction algorithm for the influence of precipitation, multi-layer, and thick clouds on the MVI, and the improvement of TPW retrieval, will be discussed in our future studies.

Acknowledgments: The authors greatly appreciate the anonymous reviewers for their valuable comments. This research was supported by the Special Foundation for Young Scientists of the State Laboratory of Remote Sensing Science (15RC-07), the National Natural Science Foundation of China (Grant No. 41501398) and the National Key Basic Research Program of China (2015CB953701).

Author Contributions: Jiancheng Shi and Dabin Ji conceived and designed the sensitivity analysis of atmosphere on MVI and the atmospheric correction algorithm for MVI; Dabin Ji, Husi Letu, Tianjie Zhao and Tianxing Wang analyzed the results of the sensitivity analysis and developed the atmospheric correction algorithm; Dabin Ji validated the results of the atmospheric correction and wrote the paper.

Conflicts of Interest: The authors declare no conflict of interest.

\section{References}

1. Chen, J.M.; Cihlar, J. Retrieving leaf area index of boreal conifer forests using Landsat TM images. Remote Sens. Environ. 1996, 55, 153-162. [CrossRef]

2. Turner, D.P.; Cohen, W.B.; Kennedy, R.E.; Fassnacht, K.S.; Briggs, J.M. Relationships between leaf area index and Landsat TM spectral vegetation indices across three temperate zone sites. Remote Sens. Environ. 1999, 70 , 52-68. [CrossRef]

3. Hu, R.; Yan, G.; Mu, X.; Luo, J. Indirect measurement of leaf area index on the basis of path length distribution. Remote Sens. Environ. 2014, 155, 239-247. [CrossRef]

4. Tucker, C.J. Red and photographic infrared linear combinations for monitoring vegetation. Remote Sens. Environ. 1979, 8, 127-150. [CrossRef]

5. Huete, A.R.; Didan, K.; Leeuwen, W.V.; Jacobson, A.; Solanos, R.; Laing, T. MODIS Vegetation Index (MOD 13) Algorithm Theoretical Basis Document Version 3.1; The University of Arizona: Tucson, AZ, USA, 1999. Available online: https://vip.arizona.edu/documents/MODIS/MODIS_VI_ATBD.pdf (accessed on 1 December 2016).

6. Shi, J.; Jackson, T.; Tao, J.; Du, J.; Bindlish, R.; Lu, L.; Chen, K.S. Microwave vegetation indices for short vegetation covers from satellite passive microwave sensor AMSR-E. Remote Sens. Environ. 2008, 112, 4285-4300. [CrossRef]

7. Choudhury, B.J.; Tucker, C.J.; Golus, R.E.; Newcomb, W.W. Monitoring vegetation using Nimbus-7 scanning multichannel microwave radiometer's data. Int. J. Remote Sens. 1987, 8, 533-538. [CrossRef]

8. Choudhury, B.J.; Tucker, C.J. Monitoring global vegetation using Nimbus-7 37 GHz Data Some empirical relations. Int. J. Remote Sens. 1987, 8, 1085-1090. [CrossRef]

9. Becker, F.; Choudhury, B.J. Relative sensitivity of normalized difference vegetation index (NDVI) and microwave polarization difference index (MPDI) for vegetation and desertification monitoring. Remote Sens. Environ. 1988, 24, 297-311. [CrossRef]

10. Min, Q.; Lin, B. Remote sensing of evapotranspiration and carbon uptake at Harvard Forest. Remote Sens. Environ. 2006, 100, 379-387. [CrossRef]

11. Li, Y.; Shi, J.; Liu, Q.; Dou, Y.; Zhang, T. The development of microwave vegetation indices from WindSat data. IEEE J. Sel. Top. Appl. Earth Obs. Remote Sens. 2015, 8, 4379-4395. [CrossRef]

12. Li, Y.; Shi, J.; Zhao, T. Effective vegetation optical depth retrieval using microwave vegetation indices from WindSat data for short vegetation. J. Appl. Remote Sens. 2015, 9, 096003. [CrossRef]

13. Olson, W.S.; Bauer, P.; Viltard, N.F.; Johnson, D.E.; Tao, W.K.; Meneghini, R.; Liao, L. A melting-layer model for passive/active microwave remote sensing applications. Part I: Model formulation and comparison with observations. J. Appl. Meteorol. 2001, 40, 1145-1163. [CrossRef] 
14. Olson, W.S.; Bauer, P.; Kummerow, C.D.; Hong, Y.; Tao, W.K. A melting-layer model for passive/active microwave remote sensing applications. Part II: Simulation of TRMM observations. J. Appl. Meteorol. 2001, 40, 1164-1179. [CrossRef]

15. Jones, A.S.; Vonder Haar, T.H. Passive microwave remote sensing of cloud liquid water over land regions. J. Geophys. Res. Atmos. 1990, 95, 16673-16683. [CrossRef]

16. Liou, K.N. An Introduction to Atmospheric Radiation, 2nd ed.; China Meteorological Press: Beijing, China, 2004; pp. 425-428.

17. Ji, D.; Shi, J.; Xiong, C.; Wang, T.; Zhang, Y. A total precipitable water retrieval method over land using the combination of passive microwave and optical remote sensing. Remote Sens. Environ. 2017, 191, 313-327. [CrossRef]

18. Jarvis, A.; Reuter, H.I.; Nelson, A.; Guevara, E. Hole-Filled Seamless SRTM Data V4. Available online: http:/ / www.cgiar-csi.org/data/srtm-90m-digital-elevation-database-v4-1 (accessed on 1 December 2016).

19. King, M.D.; Tsay, S.C.; Platnick, S.E.; Wang, M.; Liou, K.N. Cloud Retrieval Algorithms for MODIS: Optical Thickness, Effective Particle Radius, and Thermodynamic Phase. Available online: https:/ / cimss.ssec.wisc. edu/dbs/China2011/Day2/Lectures/MOD06OD_Algorithm_Theoretical_Basis_Document.pdf (accessed on 1 December 2016).

20. Menzel, W.P.; Baum, B.A.; Strabala, K.I.; Frey, R.A. Cloud Top Properties and Cloud Phase Algorithm Theoretical Basis Document Version 6, Cooperative Institute for Meteorological Satellite Studies; University of Wisconsin: Madison, WI, USA, 2002.

21. Hutchison, K.D.; Pekker, T.; Smith, S. Improved retrievals of cloud boundaries from modis for use in air quality modeling. Atmos. Environ. 2006, 40, 5798-5806. [CrossRef]

22. Wan, Z. MODIS Land-Surface Temperature Algorithm Theoretical Basis Document (LST ATBD); Institute for Computational Earth System Science: Santa Barbara, CA, USA, 1999; Volume 75.

23. Holmes, T.R.H.; De Jeu, R.A.M.; Owe, M.; Dolman, A.J. Land surface temperature from Ka band (37 GHz) passive microwave observations. J. Geophys. Res. Atmos. 2009, 114. [CrossRef]

24. Seethala, C.; Horváth, Á. Global assessment of AMSR-E and MODIS cloud liquid water path retrievals in warm oceanic clouds. J. Geophys. Res. Atmos. 2010, 115. [CrossRef]

25. Rodriguez, E.; Morris, C.S.; Belz, J.E. A global assessment of the SRTM performance. Photogramm. Eng. Remote Sens. 2006, 72, 249-260. [CrossRef]

26. Nishihama, M.; Wolfe, R.; Solomon, D.; Patt, F.; Blanchette, J.; Fleig, A.; Masuoka, E. MODIS Level 1A Earth Location: Algorithm Theoretical Basis Document Version 3.0. Available online: https://modis.gsfc.nasa. gov/data/atbd/atbd_mod28.pdf (accessed on 1 December 2016). 